\title{
Locus of Control in
}

Obsessive-Compulsive (OC) and

Depression Symptoms: The Moderating Effect of Externality on

\section{Obsessive-Related Control Beliefs in OC Symptoms}

\author{
Mujgan Inozu, Orcun Yorulmaz,' and Serife Terzi ${ }^{2}$ \\ I Uludag University, Turkey \\ ${ }^{2}$ Gazi University, Turkey
}

\begin{abstract}
Although the role of excessive efforts to exert mental control over one's unwanted intrusive thoughts has been successfully explained and documented in the cognitive-behavioural models of obsessive-compulsive disorder (OCD), individual's beliefs regarding the controllability of events, that is, locus of control (LOC), have been largely ignored in recent cognitive formulations of OCD. The present study aimed to examine the relationship between these two control-related cognitions by comparing their roles in obsessive-compulsive (OC) and depression symptoms. Measures of LOC, obsessive-related beliefs, depression, anxiety and OCD symptoms were administered to a sample of 530 Turkish university students. Results showed that while external LOC was positively associated with depression symptoms, the relation was different for OC symptoms. The interaction of LOC with a high desire for thought control was significantly associated with general OC symptoms, particularly with checking symptoms. The findings suggest that beliefs regarding the controllability of events are critical factors in OC symptomatology, but only when there is also a high desire of thought control.
\end{abstract}

Keywords: locus of control, depression, obsessive-compulsive symptoms and beliefs

Individual's beliefs regarding control have been linked to many domains of psychopathology; and, in particular, have been integrated to contemporary cognitive conceptualisations of anxiety, anxiety disorders and depression (e.g., Bandura, 1997; Clark, 2004; Purdon \& Clark, 2002). For example, the learned helplessness model of depression (Miller \& Seligman, 1973, 1975) proposes that a cognitive distortion

148 of one's ability to control one's world is a major component of a reactive affective disorder. It has been proposed that a depressed individual may have a tendency to perceive oneself as relatively ineffective in exerting control over significant life events

Address for correspondence: Orcun Yorulmaz, Department of Psychology, Faculty of Arts and Science, Uludag University, 16059 Bursa, Turkey.

E-mail: orcuny@uludag.edu.tr. 
and their outcomes. In a similar way, Barlow, Chorpita, and Turovsky (1996) have defined anxiety as a coherent cognitive-affective structure that is characterised by a 'sense of uncontrollability focused on possible future threat, danger, or other upcoming, potentially negative events' (p. 253). Consistently, many frequent symptoms in obsessive-compulsive disorder (OCD) may be understood as an individual's concern regarding the potential loss of control over his/her own thoughts and actions, and a high desire to maintain control over thoughts, actions, and the world through rituals (Clark, 2004; Purdon \& Clark, 2002).

Early cognitive models of OCD (Carr, 1974; McFall \& Wollersheim, 1979) conceptualised compulsive behaviour as an attempt to achieve a sense of control over undesired outcomes; however, in modern cognitive theories of OCD, mental control is incorporated as a product of misunderstanding normal intrusions as unacceptable/threatening. Clark's (2004) comprehensive cognitive model of OCD emphasises the role of faulty appraisals of mental control efforts over unwanted intrusive thoughts and the perceived negative consequences of failed mental control in the persistence of obsessions. Although the adverse effects of faulty appraisal of thought control and its consequences have been successfully explained and documented in OCD literature, the role of individuals' beliefs associated with controllability of life events has been largely ignored in recent cognitive formulations of OCD (Moulding \& Kyrios, 2006).

Moulding and Kyrios (2006) have suggested that two control-related beliefs, in particular, may be important to understand why individuals with OCD cannot ignore their intrusive thoughts, and feel an excessive need to perform neutralisation behaviours in response to their intrusive thoughts. The first belief is referred to as sense of control (SC), which refers to the degree to which an individual believes that a situation is controllable and that one has the skills necessary to bring about a desired outcome or prevent an undesirable outcome (Skinner, 1996). The second construct is desire for control (DC), which refers to an individual's motivation to gain control over life events (Burger \& Cooper, 1979; Deci \& Ryan, 2000; Skinner, 1996). The concept of SC is discussed within the social and behavioural science in a variety of forms, such as personal control, locus of control orientation, self-efficacy, mastery, self-directedness, personal autonomy, and helplessness (Ross \& Sastry, 1999). Locus of control (LOC) is one of the most influential concepts widely examined in the framework of sense of control. It refers to an individual's attributions of control as being either internal or external (Rotter, 1966). Individuals with a predominantly internal locus of control believe that events in their lives are controlled by themselves; in contrast, those with predominantly external locus of control believe that such events are controlled by external sources, such as chance, fate, God, powerful others, and they have little or no control on the outcomes of events in which they are involved. Although LOC and SC terms are often used interchangeably to refer to one's perceived control over life events, Skinner (1996) points out the basic conceptual differences between these two control dimensions. LOC would actually refer to the first part of sense of control that refers to an individual's belief about the controllability of situations, but not the perceived skill to control the outcomes of an event. While an external locus of control is usually accompanied by a low sense of control, it does not necessarily follow that individuals with an internal LOC have a high sense of control. For example, one may believe that events in general are dependent an skill level (i.e., internal locus of control) and at the same time believing that one does not have the skill necessary to control that event (i.e., low sense of control, for further discussion; see Skinner, 1996, 2007). In this manner, the present study mainly focused 
on examining the role of beliefs about controllability of life events in depression and obsessive-compulsive (OC) symptoms.

Since the first conceptualisation of LOC (Rotter, 1966), elaborated models of the relation between cognitions and depression have proposed that the attribution of causality that an individual makes for a traumatic event would determine the type and the extent of his/her depression. Consistently, subsequent experimental and theoretical investigations (e.g., Arnkoff \& Mahoney, 1979; Burger, 1984, 1991, 1992; Dağ, 1992, 2002; Layton, 1985; Liu et al., 2000), as well as clinical studies (e.g., Alloy \& Clements, 1992; Martin, Abramson, \& Alloy, 1984) have consistently indicated that depressed individuals have a lower internal locus of control when compared to nondepressed ones. However, different from depression studies, the role of a person's control beliefs over life events in OCD has been largely ignored. This is quite surprising, considering the salient role of the motivation of gaining control over particular emotions, thoughts, and life events, as well as fears of losing control over thoughts and actions in the maintenance and persistence of OCD symptoms (Moulding \& Kyrios, 2007).

Although few studies have investigated more general levels of DC and SC in individuals with OC-symptoms (for a review, see Moulding \& Kyrios, 2006), they have provided consistent evidence that higher levels of DC and lower SC are associated with higher levels of OCD-relevant beliefs and symptoms (e.g., Doron, Kyrios, \& Moulding, 2007; Moulding \& Kyrios, 2007; Moulding, Kyrios, Doron, \& Nedeljkovic, 2009). Based on their a series of studies (Doron et al., 2007; Moulding, Doron, Kyrios, \& Nedeljkovic, 2008; Moulding \& Kyrios, 2007; Moulding, Kyrios, \& Doron, 2007; Moulding et al., 2009), Moulding and his colleagues suggested that when an individual's sense of control does not reach the desired level, the discrepancy between SC and DC may motivate a person to perform neutralisation behaviours to regain sense of control. However, to date, only two studies have examined the relationship between LOC and OCD symptoms (Altin \& Karanci, 2008; Kennedy, Lynch, \& Schwab, 1998). Kennedy et al. (1998) examined LOC in various clinical groups presenting depression or anxiety disorders, and a normal comparison group. They found that while the internal locus of control scale scores did not differ among patient and control groups, the OCD group's externality scores were the lowest of any of the anxiety and depressive disorder patients studied. The authors suggest that OCD patients are aware of the need for internal control, and their obsessions and rituals may serve a maladaptive function to increase their internal SC and reduce their external SC. Altin and Karanci (2008) examined the relationship of LOC with responsibility appraisal in a Turkish nonclinical adolescent sample, and found that while LOC did not directly relate to OC symptoms, it moderated the effect of responsibility appraisals on OC symptoms, specifically on obsessive symptoms. They reported that a combination of high responsibility and low sense of control (i.e., external locus of control) produced the highest level of OC symptoms. As a result, their results

150 underline the importance of understanding the relationship between general control beliefs and obsessive relevant appraisals in OC symptomatology.

Cultural variables also play a role between OCD and expression of symptoms (Siev $\&$ Cohen, 2007). Consistently, several researcher have alluded to the role of cultural context in OCD-specific cognitions and symptoms. To illustrate, Yorulmaz, Gençöz, and Woody (2010) found that there were cross-cultural differences in some specific appraisals such as importance and control of thoughts among Canadian and Turkish participants. Yet, the relationship between control cognitions in OC symptoms 
severity and depression in a non-Western culture has not been thoroughly examined and thus, it is not well understood. Therefore, we aimed to examine the associations between general control beliefs and OCD-relevant control beliefs in OC and depression symptoms using a non-Western culture. In light of theoretical assertions and previous research findings, in the current study we hypothesised that external locus of control would directly relate to symptoms of depression. However, based on the findings about impact of responsibility appraisals combined with low sense of control in OC symptoms (Altin \& Karanci, 2008), we expected that an increased external LOC would increase the influence of obsessive-relevant beliefs on the severity of OC symptoms. In addition, as different OC symptoms may have different etiologies and related cognitions, we hypothesised that the association of LOC with OCD-relevant beliefs would differ in terms of different OC symptoms. However, as beliefs regarding the need to control thoughts are conceptually more similar to control variables, we expected that a low sense of control would interact with beliefs about control of intrusive thoughts, and would produce more persistent and severe OC symptoms.

\section{Method}

\section{Participants}

The sample for the study comprised 584 volunteer undergraduate university students from various departments of Uludag University in Bursa and Gazi University in Ankara, Turkey. Fifty-four (9.2\%) participants were excluded from analyses because they had received a psychiatric diagnosis at the time of the study, thus the final sample comprised 530 undergraduates. The sample comprised 376 women $(71.3 \%)$ and 154 men $(28.7 \%)$, with a mean age of $20.78(S D=1.94)$.

\section{Instruments}

Locus of Control Scale (LCS; Dag, 2002). LCS is a 47-item scale assessing whether individuals attribute the consequences of their behaviours to external or internal sources. It is a 5 -point Likert-type scale, where 1 is totally inappropriate, and 5 is totally appropriate. Possible score range is from 47 to 235 . Higher scores in this measure indicate a higher tendency to believe that life events are uncontrollable (i.e., external locus of control). The psychometric properties of the LCS for the Turkish university sample have been found satisfactory. An internal consistency analysis showed that the alpha coefficient was .92 , while a 4 -week test-retest reliability was .88 . The results of a convergent validity analyses showed that LCS correlated significantly with Internal-External Locus of Control Scale $(r=.67$; Rotter, 1966), Rosenbaum's Learned Resourcefulness Schedule ( $r=-.39$; Rosenbaum, 1980), the Symptom Check List-90 ( $r=.25$; SCL-90-R, Derogatis, 1977) and the Paranormal Beliefs Scale $(r=$ .46; Tobacyk, 1988). In the present study, the internal consistency of the LCS was high, $\alpha=.87(95 \% \mathrm{CI}=.84-.88)$.

Obsessive Beliefs Questionnaire-Revised (OBQ; Obsessive Compulsive Cognitions Working Group [OCCWG], 2003, 2005). The OBQ aims to investigate faulty belief domains which are assumed to be relatively specific to OCD. The current version of the scale has 44 items, with three subscales such as Responsibility/Threat Estimation (RT), Perfectionism/Certainty (PC) and Importance/Control of Thoughts (ICT) (OCCWG, 2005). A 7-point response format is used. The OBQ has been found to have satisfactory reliability and validity in various samples from different cultures 
(e.g., OCCWG, 2003, 2005; Yorulmaz \& Gençöz, 2008). Like the original version, the Turkish version of the OBQ was found to have good psychometric properties in both nonclinical and clinical samples (Yorulmaz \& Gençöz, 2008; Yorulmaz, Baştuğ, Tüzer, \& Göka, 2011). A proportionality agreement coefficient or Tucker phi indicated that there was a high degree of similarity between the factors of ICT (Tucker phi $=0.88)$, RT (Tucker phi $=0.92)$, and PC (Tucker phi $=0.93)$. In addition, the Turkish OBQ-44 had satisfactory internal consistency $(\alpha \mathrm{s}=.92$ for the Total Score and $.80, .86, .85$ for ICT, PC, and RT, respectively. Similarly, in the present study, the internal consistency was very high for ICT, $\alpha=.81$ (95\% CI = .78-.83); PC, $\alpha=.86(95 \% \mathrm{CI}=.84-.88)$; RT, $\alpha=.85$ (95\% CI $=.83-.87)$, and the Total Score, $\alpha=.93(95 \% \mathrm{CI}=.92-.94)$.

\section{Padua Inventory-Washington State University Revision (PI-WSUR; Burns,} Keortge, Formea, $\mathcal{E}$ Sternberger, 1996). The PI-WSUR is a 39-item scale on a 5-point response option that evaluates OCD symptoms in five dimensions: checking compulsions, contamination obsessions/cleaning compulsions, dressing/grooming compulsions, obsessive thoughts, and impulses involving harm to oneself or others. The total scale scores ranges from 0 to 156, with high scores referring to higher severity of the OCD symptoms. The original factor structure was confirmed in clinical and nonclinical samples Turkey (Yorulmaz et al., 2007), and internal consistency of the Turkish PI-WSUR were also found to be satisfactory (e.g., $\alpha=.76-.95$ ). Moreover, the Turkish version was positively related with the Maudsley Obsessive Compulsive Inventory (Rachman \& Hodgson, 1980) and Thought-Action Fusion Scale (Shafran, Thordarson, \& Rachman, 1996) among OCD patients and a nonclinical sample ( $r$ 's ranging from 0.56 to 0.84 ). In the present study, alpha coefficients were satisfactory for the total score, $\alpha=.92(95 \% \mathrm{CI}=.91-.93)$, and five subscales, $\alpha$ s $=.92$ (95\% CI $=.83-.86)$ for checking, $.85(95 \% \mathrm{CI}=.83-.86)$ for contamination/washing, $.78(95 \% \mathrm{CI}=.74-.79)$ for obsessive thoughts of harm, $.74(95 \% \mathrm{CI}=.71-.76)$ for obsessive impulsive of harm, $79(95 \% \mathrm{CI}=.76-.81)$ for grooming/dressing.

Beck Anxiety Inventory (BAI; Beck, Epstein, Brown, ES Steer, 1988). The BAI has 21 items on a 4-point response option, assessing cognitive and somatic symptoms of anxiety. The possible range of scores is 0 to 84, where higher scores correspond to higher anxiety. Ulusoy, Şahin, and Erkmen (1998) examined the Turkish version and found it to have reasonable psychometric properties with a satisfactory internal consistency and satisfactory construct validity. Furthermore, it was moderately correlated with the measures of depression, hopelessness and anxiety. In the present study, alpha coefficient of the BAI was very high, $\alpha=.92(95 \% \mathrm{CI}=.91-.92)$.

Beck Depression Inventory (BDI: Beck, Steer, $\mathcal{E}$ Garbin, 1988). The 21-item BDI evaluates depressive symptoms in emotional, somatic, cognitive and motivation domains. The scores range from 0 to 21 and higher scores represent higher severity of depressive tendency also increases. The Turkish version also revealed acceptable psychometric characteristics (Hisli, 1988). The split half reliability of the Turkish BDI-R was between .74 and .78 for university students, and .61 for depressive patients. A 4-week test-retest reliability was .65 and .73 for students and patients, respectively (Tegin, 1980; Hisli, 1988, 1989). The concurrent validity of scale, based on the correlation with the Minnesota Multiphasic personality Inventory Depression Scale, was found to be .63, for the psychiatric sample (Hisli, 1988), and .50 for a university 
sample (Hisli, 1989). In the present study, the alpha coefficient was high, $\alpha=.83$ $(95 \% \mathrm{CI}=.79-.87)$.

\section{Procedure}

The administration of the research instrument to undergraduate students was carried out during regular class hours. The rationale of the study and the criterion of voluntary participation were emphasised. Only those who signed the informed consent form were included in the study. Aside from the first part of the questionnaire set, which included an explanation and rationale of the research, the informed consent form, and sociodemographic information, the scales were presented in a randomised sequence in order to control for order effects. Each administration took approximately 30-35 minutes.

\section{Results \\ Correlation Coefficients Among Variables}

The means, standard deviations and correlations between the measures are presented in Table 1. There was a weak but significant correlation between the LCS and depression; while the LCS had no significant correlation with OCD symptoms and beliefs. Additionally, the LCS showed only a significant relationship with obsessive thoughts of harm. As expected, OCD-relevant beliefs showed a moderate-to-strong significant positive association with all symptom dimensions of OCD.

\section{The Role of LOC and OCD-Relevant Beliefs in Depression and OC Symp- toms}

Following the tests of assumptions (Tabachnick \& Fidell, 2007), separate hierarchical regression analyses were performed to explore the relative role of the LOC and OCDrelevant cognitive constructs in depression and OC symptoms. In predicting OC symptoms, the first step consisted of control variables (i.e., age, gender, depression and anxiety scores). The LCS Total Score and three subscales of OBQ were entered into the analyses in the second step. In the last step, the interaction terms between LCS and obsessive beliefs were entered into the analysis. Aside from the exclusion of depressive scores among the control variables, the same steps were also followed in predicting depression.

\section{Predictors of Depression Symptoms}

The first regression analysis was conducted to examine the roles of LOC and OCDrelevant beliefs and their interaction in the severity of depression symptoms. Table 2 shows the results of this analysis. As expected, after controlling the significant variance explained by the BAI Total score, $R^{2}$ Change $=.13, \beta=.34, t(500)=8.28, p<.001$, in step 2 the LCS Total score was the only significant predictor of a depressive tendency. A higher level of externality was significantly associated with higher levels of symptoms of depression, $R^{2}$ Change $=.07, \beta=20, t(500)=5.08, p<.001$. On the other hand, OBQ subscales and the interaction of LCS with obsessive beliefs did not contribute significantly to the explanatory power of the model. The predictors accounted for $20 \%$ of the variance in BDI. 
TABLE 1

Mean Scores, Standard Deviations, Intercorrelations, and Reliability Coefficients for the Variables

\begin{tabular}{|c|c|c|c|c|c|c|c|c|c|c|c|c|}
\hline & LOC & BDI & BAI & PI-Total & $\begin{array}{l}\text { PI-R } \\
\text { Cleaning }\end{array}$ & $\begin{array}{l}\text { PI-R } \\
\text { Grooming }\end{array}$ & $\begin{array}{l}\text { Pl-R } \\
\text { Checking }\end{array}$ & $\begin{array}{l}\text { PI-R } \\
\text { Obse.Harm }\end{array}$ & $\begin{array}{l}\text { PI-R } \\
\text { Impl.Harm }\end{array}$ & $\begin{array}{l}\text { OBQ- } \\
44-R T\end{array}$ & $\begin{array}{l}\text { OBQ- } \\
44-P C\end{array}$ & $\begin{array}{l}\text { OBQ- } \\
44-I C T\end{array}$ \\
\hline LOC & $117.82(18.15)$ & & & & & & & & & & & \\
\hline BDI & $.23^{* *}$ & $10.84(7.59)$ & & & & & & & & & & \\
\hline BAI & .06 & $.33^{* *}$ & $17.74(12.07)$ & & & & & & & & & \\
\hline PI-R Total & .07 & $.29 * *$ & $.35^{* *}$ & $45.04(21.75)$ & & & & & & & & \\
\hline PI-R Cleaning & -.06 & $.17^{* *}$ & $.23^{* *}$ & $.84^{* *}$ & 18.48 (9.39) & & & & & & & \\
\hline PI-R Grooming & .04 & $.15^{* *}$ & $.21^{* *}$ & $.64^{* *}$ & $.51 * *$ & $4.07(3.29)$ & & & & & & \\
\hline PI-R Checking & .07 & $.20 * *$ & $.28^{* *}$ & $.84^{* *}$ & $.54^{* * *}$ & $.46 * *$ & $12.37(7.94)$ & & & & & \\
\hline PI-R Obs.Harm & $.11^{*}$ & $.38^{* *}$ & $.36^{* *}$ & $.77^{* *}$ & $.51 * *$ & $.41^{* *}$ & $.62^{* *}$ & $6.90(4.29)$ & & & & \\
\hline PI-R Imp.Harm & .07 & $.29 * *$ & $.23^{* *}$ & $.44^{* *}$ & $.16^{* *}$ & $.12^{*}$ & $.26^{* *}$ & $.36^{* *}$ & $3.19(3.98)$ & & & \\
\hline OBQ-44-RT & .04 & $.25^{* *}$ & $.29 * *$ & $.55^{* *}$ & $.40^{* * *}$ & $.35 * *$ & $.47^{* *}$ & $.54 * *$ & $.24 * *$ & $61.36(14.69)$ & & \\
\hline OBQ-44-PC & .02 & $.24^{* *}$ & $.19 * *$ & $.53^{* *}$ & $.42 * *$ & $.42 * *$ & $.44 * *$ & $.42 * *$ & $.19^{*}$ & $.64^{* *}$ & $67.97(14.46)$ & \\
\hline ОВО-44-ІСТ & .02 & $.15^{* *}$ & $.22^{* *}$ & $.45^{* *}$ & $.34^{* * *}$ & $.28^{* *}$ & $.39^{* *}$ & $.43^{* *}$ & $.19^{*}$ & $.66^{* *}$ & $.55^{* *}$ & $38.42(12.12)$ \\
\hline
\end{tabular}

Note: Means, and standard deviations (in parentheses) are given on diagonal. LOC = Locus of Control Scale; BDI = Beck Depression Inventory; BAI = Beck Anxiety Inventory; PI-R Total = Padua Inventory- Revised; PI-R Cleaning = Contamination/Washing; PI-Grooming = Grooming/Dressing; PI-R Obs. Harm = Obsessive Thoughts of Harm; PI-R Imp.Harm = Obsessive Impulsive of Harm; OBQ-RT = OBQ Responsibility/Overestimation of Threat; OBQ-PC = OBQ Perfectionism/Intolerance of

Uncertainty; OBQ-ICT = OBO Importance of Thoughts/Need to Control Thoughts.

${ }^{*} p<.05,{ }^{* *} p<.001$ 


\section{TABLE 2}

Summary of the Six Separate Hierarchical Multiple Regression Analyses for Predicting OC-Symptoms and Depression

\begin{tabular}{|c|c|c|c|c|}
\hline BDI & $\beta$ & $t$ & $R^{2} \Delta$ & $\mathrm{F} \Delta$ \\
\hline Step 1 & & & .13 & $18.91 * * *$ \\
\hline BAI & .34 & $8.28 * * *$ & & \\
\hline Step 2 & & & .07 & $11.78 * * *$ \\
\hline LOC & .20 & $5.08 * * *$ & & \\
\hline \multicolumn{5}{|l|}{ PI Total } \\
\hline Step 1 & & & .16 & $25.66 * * *$ \\
\hline Age & -.11 & $-2.79 * *$ & & \\
\hline BDI & .22 & $5.25 * * *$ & & \\
\hline BAI & .24 & $5.71 * * *$ & & \\
\hline Step 2 & & & .22 & $62.74 * * *$ \\
\hline OBQ-RT & .28 & $5.39 * * *$ & & \\
\hline OBQ-PC & .23 & $5.09 * * *$ & & \\
\hline Step 3 & & & .01 & $4.57^{*}$ \\
\hline OBQ-ICT*LOC & .08 & $2.13^{*}$ & & \\
\hline \multicolumn{5}{|c|}{ PI-R Cleaning/Washing } \\
\hline Step 1 & & & .07 & $10.46^{* * *}$ \\
\hline Age & -.09 & $-2.03 * *$ & & \\
\hline Gender & .10 & $2.39 * *$ & & \\
\hline BDI & .11 & $2.41 * * *$ & & \\
\hline BAI & .16 & $3.59 * * *$ & & \\
\hline Step 2 & & & .15 & $34.95^{* * *}$ \\
\hline OBQ-RT & .16 & $2.78 * * *$ & & \\
\hline OBQ-PC & .26 & $4.96 * * *$ & & \\
\hline \multicolumn{5}{|c|}{ PI-R Checking Compulsions } \\
\hline Step 1 & & & .11 & $16.93 * * *$ \\
\hline Gender & -.14 & $-3.58 * * *$ & & \\
\hline BDI & .14 & $3.27 * * *$ & & \\
\hline BAI & .22 & $5.02 * * *$ & & \\
\hline Step 2 & & & .22 & $40.20 * * *$ \\
\hline OBQ-RT & .26 & $4.68 * * *$ & & \\
\hline OBQ-PC & .18 & $3.59 * * *$ & & \\
\hline Step 3 & & & .01 & $6.71 *$ \\
\hline OBQ-ICT*LOC & .08 & $2.59 *$ & & \\
\hline \multicolumn{5}{|c|}{ PI-R Dressing/Grooming } \\
\hline Step 1 & & & .06 & $8.18^{* * *}$ \\
\hline Age & -.09 & $-2.01 *$ & & \\
\hline BAI & .17 & $3.79 * * *$ & & \\
\hline
\end{tabular}


TABLE 2

Continued

\begin{tabular}{|c|c|c|c|c|}
\hline BDI & $\beta$ & $t$ & $R^{2} \Delta$ & $\mathrm{F} \Delta$ \\
\hline Step 2 & & & .13 & $22.04 * * *$ \\
\hline OBQ-RT & .12 & $2.04 * * *$ & & \\
\hline OBQ-PC & .28 & $5.20 * * *$ & & \\
\hline \multicolumn{5}{|c|}{ PI-R Obsessive thoughts of harm } \\
\hline Step 1 & & & .19 & $31.20 * * *$ \\
\hline Age & -.11 & $-2.80^{*}$ & & \\
\hline BDI & .30 & $7.21 * * *$ & & \\
\hline BAI & .20 & $4.85 * * *$ & & \\
\hline Step 2 & & & .19 & $53.38 * * *$ \\
\hline OBQ-RT & .38 & $7.25^{* * *}$ & & \\
\hline OBQ-PC & .10 & $1.98^{*}$ & & \\
\hline \multicolumn{5}{|c|}{ PI-R Obsessive Impulses of Harm } \\
\hline Step 1 & & & .13 & $19.03^{* * *}$ \\
\hline Gender & -.16 & $-3.77 * * *$ & & \\
\hline BDI & .26 & $5.91 * * *$ & & \\
\hline BAI & .12 & $2.62 * * *$ & & \\
\hline
\end{tabular}

Note: $\mathrm{LOC}=$ Locus of Control Scale, BDI = Beck Depression Inventory; BAI = Beck Anxiety Inventory; $\mathrm{PI}-\mathrm{R}=$ Padua Inventory Revised; OBQ-RT = OBQ Responsibility/Overestimation of Threat; OBQ-PC = OBQ Perfectionism/Intolerance of Uncertainty; OBQ-ICT = OBQ Importance of Thoughts/Need to Control Thoughts.

${ }^{*} p<.05,{ }^{*} p<.01, * * * p<.001$.

For ease of understanding, values for the nonsignificant variables are excluded. Each value is taken from the represented steps.

\section{Predictors of OC Symptoms}

The results of the regression analyses are also presented in Table 2, and it can be seen that among the control variables, which explained $16 \%$ of the variance, the depression, $\beta=.22, t(500)=5.25, p<.001)$, anxiety, $\beta=.24, t(500)=5.71, p<$ .001 , and age scores, $\beta=-.11 t(500)=-2.79, p<.001$, had a significant association with the PI-WSUR Total Score. After excluding this variance, the second step, which comprised the OBQ subscales and LCS scores, explained $22 \%$ of the total variance, but only the subscales of RT, $\beta=.28, t(496)=5.39, p<.001$, and PC, $\beta=.23$, $t(496)=5.09, p<.001$, significantly predicted the PI-WSUR Total Score. In the last step, the interaction of LCS with ICT subscale weakly but significantly improved the explained variance in the PI- WSUR Total Score, $\beta=0.8, t(490)=2.13, p<.05$.

156 All these variables combined accounted for $39 \%$ of the variance.

To better understand the nature of the significant interaction between LCS and ICT beliefs, whether the slopes of these two regression lines significantly differed from zero was tested following the procedure outlined by Aiken and West (1991). According to this procedure, simple regression lines for moderated variables are plotted for significant interaction effects using centered data. Figure 1 suggests that types of locus of control orientation affected individuals differently, depending on their level of beliefs about the importance and control of thoughts in determining OC symptoms. 


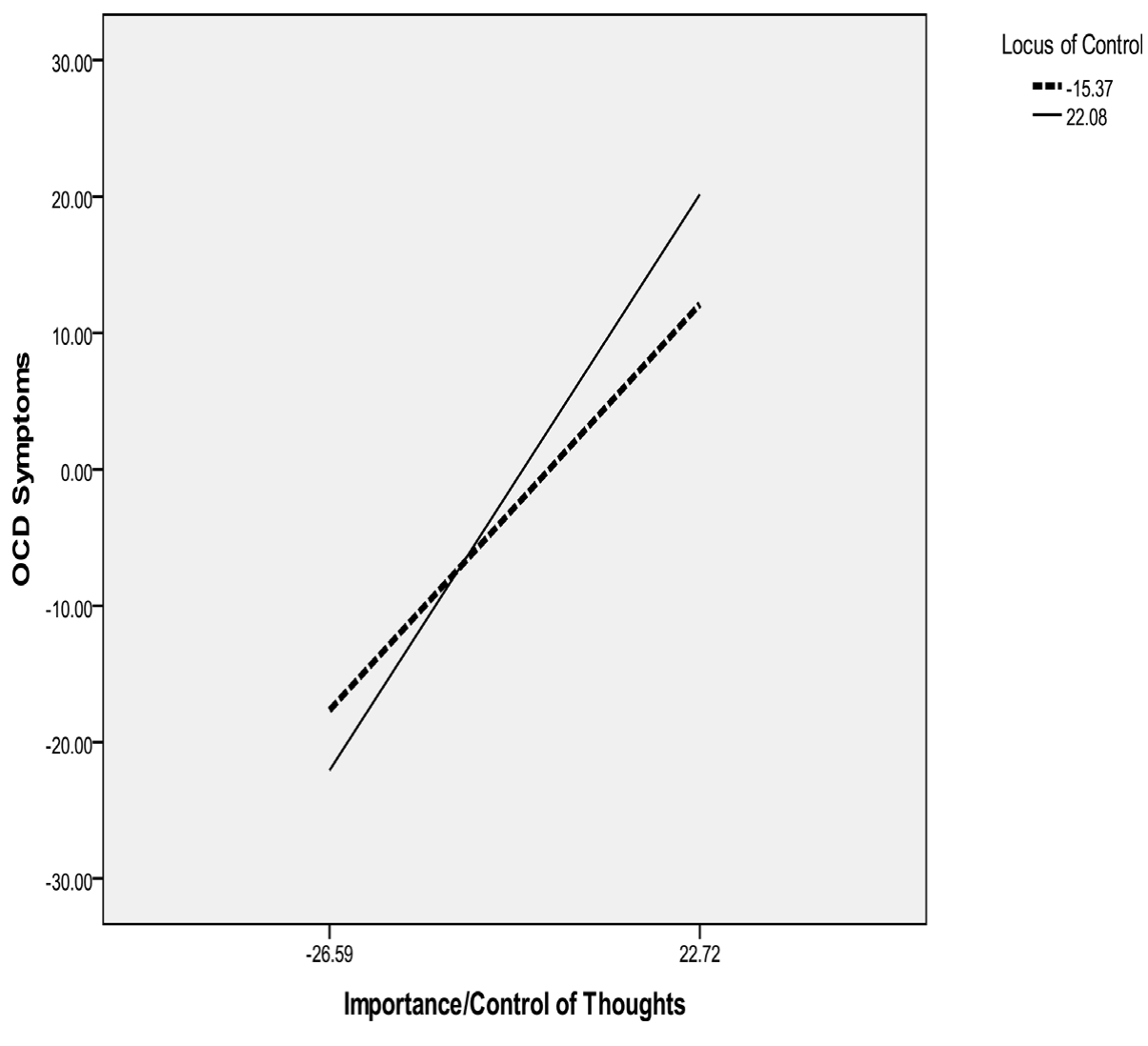

FIGURE 1

Interaction between importance/control of thoughts and locus of control in the prediction of OCD symptoms.

The results revealed that the simple slope test was only significant for high levels of ICT; simple slope $\beta=.29, t(543)=4.71, p<.001$. That is, it would appear that the degree of an individual's beliefs about the controllability of life events is only important for defining the severity of OC symptoms when an individual's belief in the importance and the control of thoughts is high. For the subjects with high ICT beliefs, OC symptom severity was lower among those with an internal locus of control than those with an external locus of control. However, for participants with low ICT beliefs, the simple slope was not significant, indicating that their levels of OC symptoms were low regardless of their level of locus of control.

\section{Predictors of OC Symptom Dimensions}

After examining the predictors of general OC symptoms, the predictors of the symptom subtypes were examined, and as can be seen from the Table 2, the results of the regression analyses revealed some $\mathrm{OC}$ symptom differentiations. To illustrate, among the control variables, the participants' age showed a significant negative association with cleaning, dressing/grooming, and obsessive thoughts of harm. Moreover, while 


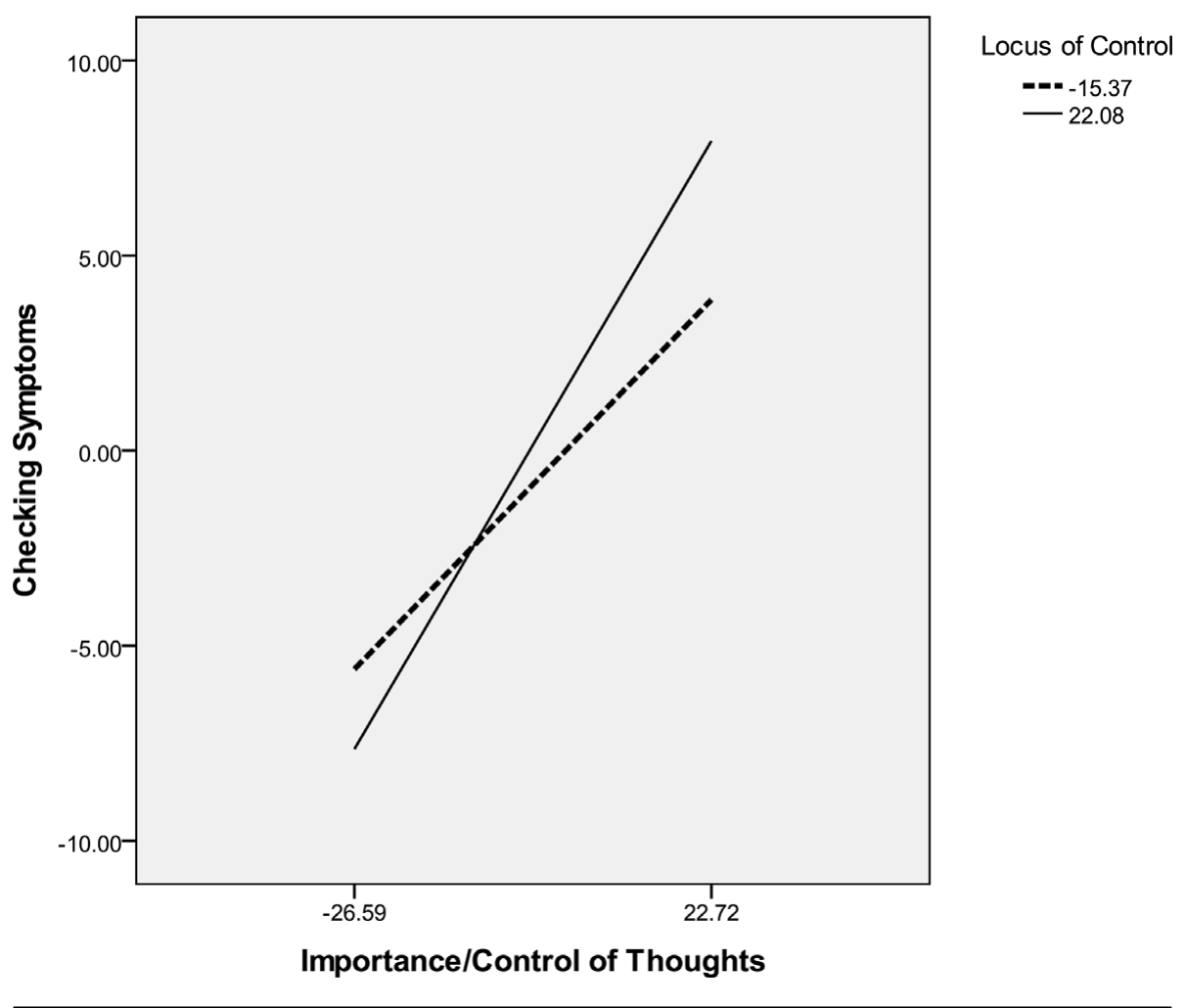

FIGURE 2

Interaction between importance/control of thoughts and locus of control in the prediction of checking symptoms.

being male predicted the symptoms of checking and obsessive impulses of harm, being female was more related to cleaning/washing symptoms. After controlling the influence of the control variables in the first step, LCS did not predict any OC symptoms. RT and PC beliefs were significantly associated with all OC symptoms, except in the PI-WSUR Obsessive Impulses of Harm subscale. Finally, the interaction between LCS and ICT subscale was only weakly but significantly related to the PIWSUR Checking subscale.

As seen in Figure 2, the simple slope coefficient for the checking of LCS at the two levels of ICT beliefs (i.e., low and high) was significant only for high ICT belief levels; simple slope $\beta=.11, t(543)=2.05, p<.05$. The combination of externality and the over-importance of thought and control beliefs produced the highest degree of checking symptoms, whereas the simple slope was not significant for participants with low ICT beliefs, suggesting that their levels of OC symptoms were low, regardless of their levels of locus of control.

\section{Discussion}

In this study, the relationship between the LOC and obsessive-related beliefs to OC and depression symptoms was examined comparatively in a nonclinical undergraduate 
sample. Based on previous findings, it was hypothesised that while LOC would show a direct relationship with the severity of symptoms of depression, it would interact with obsessive-related beliefs, in particular, with the importance of thought and control beliefs, to increase OC symptom severity. Furthermore, consistent with the suggestion that a discrepancy in control beliefs may be a trigger for engaging in OC symptoms we predicted that the combination of high desire for control of thoughts and external locus of control (i.e., a low sense of control) would relate more strongly to symptom dimensions with overt compulsive features, such as checking and cleaning, as opposed to obsessional impulses of harm and thoughts of harm. Consistent with the hypotheses, it was found that while greater external locus of control was significantly associated with greater levels of depressive symptoms, LOC did not show any significant relationship with either general OC symptom severity or any OC symptom dimensions. On the other hand, the interaction of LOC with importance and control of beliefs predicted weakly but significantly the severity of general OC symptoms as well as symptoms of checking.

The finding that LOC is a predictor of depressive symptoms is consistent with the theoretical importance of control beliefs in depressive symptoms. Since Rotter's (1966) original work, most studies conducted on samples of students and other groups have revealed that LOC externality level has a positive relationship with depressive symptoms (Burger, 1984; Dyal, 1984; Ganellen \& Blaney, 1984; Holder \& Levi, 1988; Lester, 1989; Whitman, Desmond, \& Price, 1987). Furthermore, Martin et al. (1984) found that clinically depression was related to low internality and high externality, supporting similar research findings among student populations. More importantly, the present study revealed that, consistent with the cognitive model of OCD, general control beliefs did not interact with any OCD-relevant beliefs to predict more severe depressive symptoms. These findings suggest that in spite of a high commorbity between depression and OCD (e.g., Fireman, Koran, Leventhal, \& Jacabson, 2001; Samuels \& Nesdadt, 1997), OCD-relevant cognitions still seem to be a unique feature of OCD.

The studies conducted by Keinan $(1994,2002)$ showed that when the desire for control is increased, or the individual's sense of control is endangered, the individual is motivated to increase his/her subjective sense of control, even when the beliefs and actions used for this enhancement are implausible. Consistently, the results of the present study showed that the interaction between LOC and beliefs about the importance and control of thought was significantly associated with general OC symptoms and specifically checking symptoms. These results suggest that when external locus of control, which indicates the presence of decreased sense of control, is combined with a high desire to control thoughts, this increased discrepancy may motivate a person to perform actions to decrease the discrepancy between the perceived and desired control by performing compulsive checking. Therefore, checking symptoms may be seen as an attempt to regain control over external events. Once anxiety reduction and sense of control has been achieved through compulsive behaviours, such as in the case of checking, people with OCD may experience relief and may stop the ritual activity. Unfortunately, the relief is short-lived, anxiety returns, and the ritualised activity must be re-performed (Magril, Dar, \& Liberman, 2008; Salkovkis, 1985).

The specific relationship between control beliefs and checking symptoms is also consistent with the hypothesis of this study. As suggested by Moulding and Kyrios (2007), a higher DC and lower SC would relate more strongly to the symptom dimensions with overt compulsive features (e.g., checking and contamination/washing 
obsessions), but not covert compulsive features, such as obsessional impulses of harm or thoughts of harm. This is consistent with the suggestion that discrepancies in control beliefs may be a factor in motivating actions within OCD. However, the interaction between LOC and beliefs about the importance/control of thoughts was not significantly related to cleaning/washing symptoms. While this finding was not predicted, as a past study has linked control cognitions to contamination obsessions/washing compulsions rather than checking (Doron et al., 2007), it is possible that contamination and checking symptoms may be related to different control beliefs. As suggested by different researchers (Rachman, 2004; Steketee, Grayson, \& Foa, 1985), individuals with contamination obsessions are characterised by attempts to control their immediate environments, while checking symptoms are more related to ensuring the prevention of future harm. Therefore, this nonsignificant association of LOC with desire for thought control in terms of cleaning symptoms may be a result of item characteristics of LCS, which are mostly related to general control beliefs and control over future events, rather than an individual's immediate environment. Hence, this result should be replicated in future studies using different control measures.

The present study presents some limitations. First, the sample used in this study comprised a nonclinical university student from within a limited age range. In particular, as previous literature has indicated that the relationship between LOC and psychopathology may vary according to demographic variables such as age (Lachman, 1990), sex (Weisz, Rothbaum, \& Blackburn, 1984), and ethnicity (Lefcourt, 1972), it is important to examine the relationship between LOC and OC symptoms in different age and education groups. Although most of the previous studies reported that almost $80 \%$ of nonclinical subjects experienced unwanted intrusive thoughts that have very similar content as seen in clinical obsessions (e.g., Rachman \& de Silva, 1978; Salkovskis \& Harrison, 1984), the concepts examined in the present study are closely related to psychopathology and thus it is also strongly encouraged to examine these constructs in clinical samples. Additionally, the cross-sectional nature and the inclusion of general locus of control measures may also contribute to the limitations of the study. Accordingly, a replication of the present findings in clinical groups having received psychiatric diagnoses in studies with different methodologies (e.g., longitudinal) and alternative instruments will provide a clearer understanding of the role of control beliefs in OCD.

To conclude, the results of this study support the specificity of obsessive-related beliefs with OC symptoms, indicating these beliefs not showing any association with symptoms of depression in a young adult sample from a non-Western country, Turkey. The results seem to support the theoretical consistency of OC symptomatology in the international context. More importantly, the results point out the facilitating role of external locus of control when coupled with a high level of desire to control thoughts in OC symptoms, particularly, in checking symptoms. These novel findings suggest that understanding possible interaction between different control constructs would improve our understanding of phenomenology of OCD, and could help clinicians and researchers to develop more comprehensive cognitive formulations of OCD.

\section{References}

Aiken, L.S., \& West, S.G. (1991). Multiple regression: Testing and interpreting interactions. Newbury Park: Sage. 
Alloy, L.B., \& Clements, C.M. (1992). Illusion of control: Invulnerability to negative affect and depressive symptoms after laboratory and natural stressors. Journal of Abnormal Psychology, 101, 234-245.

Altin, M., \& Karanci, N. (2008). How does locus of control and inflated sense of responsibility related to obsessive-compulsive symptoms in Turkish adolescents? Journal of Anxiety Disorders, 22, 1303-1315.

Arnkoff, D.B., \& Mahoney, M.J. (1979). The role of perceived control in psychopathology. In L.C. Perlmuter \& R.D. Monty (Eds.), Choice and perceived control (pp. 155-174). Hillsdale, NJ: Erlbaum.

Bandura, A. (1997). Self-efficacy: The exercise of control. New York: Freeman.

Barlow, D.H., Chorpita, B.F., \& Turovsky, J. (1996). Fear, panic, anxiety, and disorders of emotion. Nebraska Symposium on Motivation, 43, 251-328.

Beck, A.T., Epstein, N., Brown, G., \& Steer, R.A. (1988). An inventory for measuring clinical anxiety: Psychometric properties. Journal of Consulting and Clinical Psychology, 56, 893-897.

Beck, A.T., Steer, B.F., \& Garbin, M.G. (1988). Psychometric properties of the Beck Depression Inventory: Twenty-five years of evaluation. Clinical Psychology Review, 8, 77-100.

Burger, J.M. (1984). Desire for control, locus of control and proneness to depression. Journal of Personality, 52, 71-89.

Burger, J.M. (1991). The effects of desire for control in situations with chance-determined outcomes: Gambling behaviour in lotto and bingo players. Journal of Research in Personality, 25, 196-204.

Burger, J.M. (1992). Desire for control: Personality, social, and clinical perspectives. New York: Plenum Press.

Burger, J.M., \& Cooper, H.M. (1979). The desirability of control. Motivation and Emotion, 3, 381-393.

Burns, G.L., Keortge, S.G., Formea, G.M., \& Sternberger, L.G. (1996). Revision of the Padua Inventory of obsessive compulsive disorder symptoms: Distinctions between worry, obsessions, and compulsions. Behaviour Research and Therapy, 34, 163-173.

Carr, A.T. (1974). Compulsive neurosis: A review of the literature. Psychological Bulletin, 81, 311-318.

Clark, D.A. (2004). Cognitive-behavioral therapy for OCD. New York: Guilford.

Dağ, I. (1992). Kontrol odağı, öğrenilmiş güçlülük ve psikopatoloji ilişkileri [Relationships between locus of control, learned resourcefulness, and psychopathology]. Psikoloji Dergisi [Turkish Journal of Psychology], 7, 1-9.

Dağ, I. (2002). Kontrol Odağı Ölçeği (KOÖ): Ölçek geliştirme, güvenirlik ve geçerlilik çalışması [Psychometric Properties of Locus of Control Scale]. Türk Psikoloji Dergisi [Turkish Journal of Psychology], 17, 77-90.

Deci, E.L., \& Ryan, R M. (2000). The 'what' and 'why' of goal pursuits: Human needs and the self-determination of behavior. Psychological Inquiry, 11, 227-268.

Derogatis, L.R. (1977). SCL-90: Administration, scoring, and procedures manual I for the R (revised) version of the psychopathology rating scale series. Baltimore, MD: Johns Hopkins University School of Medicine.

Doron, G., Kyrios, M., \& Moulding, R. (2007). Sensitive domains of self-concept in ObsessiveCompulsive Disorder: Further evidence for a multidimensional model of OCD. Journal of Anxiety Disorders, 21, 433-444.

Dyal, J.A. (1984). Cross-cultural research with the locus of control construct. In H.M. Lefcourt (Eds.), Research with the locus of control construct: Vol. 3. Extensions and limitations (pp. 209-306). New York: Academic Press.

Fireman, M.S., Koran, L.M., Leventhal, J.L., \& Jacabson, A. (2001). The prevalence of clinically recognized obsessive-compulsive disorder in a large health maintenance organization. American Journal of Psychiatry, 158, 1904-1910.

Ganellen, R.J. \& Blaney, P.H. (1984). Stress, externality and depression. Journal of Personality, 52, 326-337.

Hisli, N. (1988) Beck Depresyon Envanteri'nin geçerliği üzerine bir çalışma [A study on the validity of Beck Depression Inventory]. Psikoloji Dergisi [Turkish Journal of Psychology], 6, 118-122. 
Hisli, N. (1989) Beck Depresyon Envanteri'nin üniversite öğrencileri için geçerliği ve [Reliability and validity of Beck Depression Inventory for university students]. Dergisi [Turkish Journal of Psychology], 7, 3-13.

Holder, E.E., \& Levi, D.J. (1988). Mental health and locus of control: SCL-90_R and Levenson's IPC Scales. Journal of Clinical Psychology, 44, 753-755.

Keinan, G. (1994). Effects of stress and tolerance of ambiguity on magical thinking. Journal of Personality and Social Psychology, 67, 48-55.

Keinan, G. (2002). The effects of stress and desire for control on superstitious behaviour. Personality and Social Psychology Bulletin, 28, 102-108.

Kennedy, B.L., Lynch, G.V., \& Schwab, J.J. (1998). Assessment of locus of control in patients with anxiety and depressive disorders. Journal of Clinical Psychology, 54, 509-515.

Lachman, M.E. (1990). When bad things happen to older people: Age differences in attributional style. Psychology and Aging, 5, 607-609.

Layton, C. (1985). The relationship between externality and general, nonpsychotic psychiatric morbidity in normal males. Perceptual and Motor Skills, 61, 746.

Lefcourt, H.M. (1972). Recent developments in the study of locus of control. In B.A. Maher (Ed.), Progress in experimental personality research (Vol. 6, pp. 1-39). New York: Academic Press.

Lester, D. (1989). Locus of control, depression and suicidal ideation. Perceptual and Motor Skills, 69, 1158.

Liu, X., Kurita, H., Uchiyama, M., Okawa, M., Liu, L., \& Ma, D. (2000). Life events, locus of control, and behavioral problems among Chinese adolescents. Journal of Clinical Psychology, 56, 15651577.

Magril, O.R., Dar, R., \& Liberman, N. (2008). Illusion of control and behavioral control attempts in obsessive- compulsive disorder. Journal of Abnormal Psychology, 117, 334-341.

Martin, D.J., Abramson, L.Y., \& Alloy, L.B. (1984). The illusion of control for self and others in depressed and nondepressesd college students. Journal of Personality and Social Psychology, 46, $125-136$.

McFall, M.E., \& Wollersheim, J.P. (1979). Obsessive-compulsive neurosis: A cognitive- behavioral formulation and approach to treatment. Cognitive Therapy and Research, 3, 333-348.

Miller, W.R., \& Seligman, M.E.P. (1973). Depression and the perception of reinforcement. Journal of Abnormal Psychology, 82, 62-73.

Miller, W.R., \& Seligman, M.E.P. (1975). Depression and learned helplessness in man. Joumal of Abnormal Psychology, 84, 228-238.

Moulding, R., Doron, G., Kyrios, M., \& Nedeljkovic, M. (2008). Desire for control, sense of control and obsessive-compulsive symptoms: An extension to clinical sample. Journal of Anxiety Disorder, 22, 1472-1479.

Moulding, R., Kyrios, M., Doron, G., \& Nedeljkovic, M. (2009). Mediated and direct effect of general control beliefs on obsessive compulsive symptoms. Canadian Journal of Behavioural Science, 2, 8492.

Moulding, R., \& Kyrios, M. (2006). Anxiety disorders and control-related beliefs: The exemplar of obsessive-compulsive disorder (OCD). Clinical Psychology Review, 26, 573-583.

Moulding, R., \& Kyrios, M. (2007). Desire for control, sense of control and obsessive-compulsive symptoms. Cognitive Therapy and Research, 31, 759-772.

Moulding, R., Kyrios, M., \& Doron, G. (2007). Obsessive-compulsive behaviours in specific situations: the relative influence of appraisals of control, responsibility and threat. Behaviour Research and Therapy, 45, 1693-1702.

Obsessive Compulsive Cognitions Working Group. (2003). Psychometric validation of the obsessive belief questionnaire and the interpretation of intrusions inventory: Part 2. Behaviour Research and Therapy, 41, 863-878.

Obsessive Compulsive Cognitions Working Group. (2005). Psychometric validation of the obsessive belief questionnaire and interpretation of intrusions inventory-Part 2: Factor analyses and testing of a brief version. Behaviour Research and Therapy, 43, 1527-1542. 
Purdon, C., \& Clark, D.A. (2002). The need to control thoughts. In R.O. Frost \& G. Steketee (Eds.), Cognitive approaches to obsessions and compulsions: Theory, assessment and treatment (pp. 29-43). Oxford: Elsevier.

Rachman, S. (2004). Fear of contamination. Behaviour Research and Therapy, 42, 1227-1255.

Rachman, S., \& de Silva, P. (1978). Abnormal and normal obsessions. Behaviour Research and Therapy, $31,1449-1454$.

Rachman, S., \& Hodgson, R.J. (1980). Obsessions and compulsions. Englewood Cliffs, NJ: Prentice.

Rosenbaum, M.A. (1980). A schedule for assessing self-control behaviors: Preliminary findings. Behavior Therapy, 11, 109-121.

Ross, C.E., \& Sastry, J. (1999). The Sense of personal control: Social structural causes and emotional consequences. In C. Aneshensel \& J.C. Phelan (Eds.), The handbook of the sociology of mental health and illness (pp. 369-394). New York: Plenum.

Rotter, J.B. (1966). Generalized expectancies for internal and external control for reinforcement. Psychological Monographs, 80, 1-28.

Salkovskis, P.M. (1985). Obsessional-compulsive problems: A cognitive behavioural analysis. Behaviour Research and Therapy, 23, 571-583.

Salkovskis, P.M., \& Harrison, J. (1984). Abnormal and normal obsessions: A replication. Behaviour Research and Therapy, 22, 549-552.

Samuels, J., \& Nestadt, G. (1997). Epidemiology and genetics of obsessive-compulsive disorder. International Review of Psychiatry, 9, 67-72.

Shafran, R., Thordarson, D., \& Rachman, S. (1996). Thought-action fusion in obsessive-compulsive disorder. Journal of Anxiety Disorders, 10, 379-391

Siev, J., \& Cohen, A.B. (2007). Is thought-action fusion related to religiosity? Differences between Christians and Jews. Behaviour Research and Therapy, 45, 829-837.

Skinner, E.A. (1996). A guide to constructs of control. Journal of Personality and Social Psychology, $71,549-570$.

Skinner, E. A. (2007). Secondary control critiqued: Is it secondary? Is it control? Comment on Morling and Evered (2006). Psychological Bulletin, 6, 911-916.

Steketee, G., Grayson, J.B., \& Foa, E.B. (1985). Obsessive-compulsive disorder: Differences between washers and checkers. Behaviour Research and Therapy, 23, 197-201.

Tabachnick, B.G., \& Fidell, L. (2007). Using multivariate statistics. Boston: Pearson Education.

Tegin, B. (1980) Depresyonda bilişsel bozukluklar: Beck modeline göre bir inceleme [Cognitive impairments in depression: an analysis according to Beck's modell. (Unpublished doctoral dissertation). Hacettepe University, Ankara.

Tobacyk, J.J. (1988). A Revised Paranormal Belief Scale. Unpublished manuscript. Louisiana Tech University, Ruston, LA.

Ulusoy, M., Şahin, N.H., \& Erkmen, H. (1998). Turkish version of the Beck Anxiety Inventory: Psychometric properties. Journal of Cognitive Psychotherapy, 12, 163-172.

Weisz, J.R., Rothbaum, F.M., \& Blackburn, T.C. (1984). Standing out and standing in. American Psychologist, 39, 955-969.

Whitman, L., Desmond, S.M., \& Price, J.H. (1987). Development of a depression locus of control scale. Psychological Reports, 60, 583-589.

Yorulmaz, O., Baştuğ, B., Tüzer, V., \& Göka, E. (2011). Biased appraisal, cognitions and thought control efforts in Turkish patients with OCD. Manuscript sent for publication.

Yorulmaz, O., \& Gençöz, T. (2008). Psychometric properties of three questionnaires that evaluate appraisal and control processes in OCD symptoms. Turkish Psychological Articles, 11, 1-13.

Yorulmaz, O., Gençöz, T., \& Woody, S. (2010). Vulnerability factors in OCD symptoms: Crosscultural comparisons between Turkish and Canadian Samples. Clinical Psychology and Psychotherapy, 17, 110-121.

Yorulmaz, O., Karancı, A.N., Dirik, G., Baştuğ, B., Kısa, C., Göka, E., \& Burns, G.L. (2007). Padua Inventory-Washington State University Revision: Psychometric properties of the Turkish Version. Turkish Psychological Articles, 10, 75-85. 